FETAL AND NEONATAL EDITION

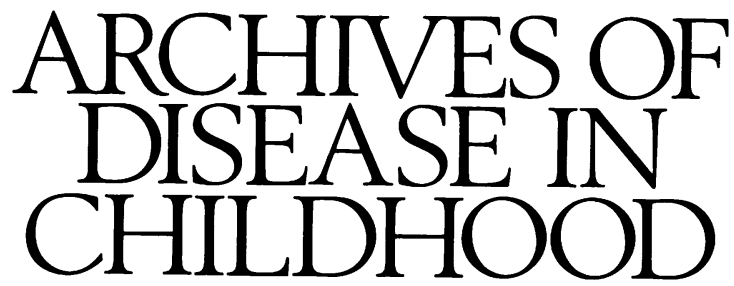

\title{
How does exogenous surfactant work?
}

As a result of the classical studies of Avery and Mead, over 30 years ago, ${ }^{1}$ we know that the lungs of babies with respiratory distress syndrome are relatively non-compliant, requiring high pressures to drive in even relatively small amounts of air. These studies also showed that mechanical problems are due to a lack of surfactant leading to high surface tension forces at the air water interface within the alveoli.

It therefore came as something of a surprise when a number of reports claimed that although there was often a dramatic improvement in oxygenation soon after the administration of exogenous, particularly natural, surfactant, ${ }^{2}$ this was not matched by a simultaneous improvement in compliance. ${ }^{3-6}$ This often lagged behind the improvements in gaseous exchange by as much as up to 24 hours. A further concern was that a number of babies with classical respiratory distress syndrome, in one series $22 \%,{ }^{7}$ failed to show any benefit after surfactant treatment and indeed, sometimes deteriorated considerably. This has led to considerable interest in the effects of surfactant administration on the lungs of babies with respiratory distress syndrome.

One of the first interesting pieces of information was that a good clinical response to surfactant was associated with clearing of the chest radiograph, ${ }^{2}$ suggesting that surfactant treatment was accompanied by an increase in the functional residual capacity (FRC); this is the volume of gas remaining in the lungs at the end of a respiratory cycle. Since then it has proved possible to measure this volume using gas dilation techniques even in babies requiring ventilatory support. ${ }^{8}$ This technique involves inserting a 'bag in a bottle' device between the endotracheal tube and the ventilator circuit so that for a period of up to a minute the baby is ventilated solely by the gas within the bag. At the beginning of the measurement, the volume of gas and the concentration of the tracer gas, usually argon or helium, which are both insoluble in water, are measured. The FRC can then be calculated from the fall in concentration of the marker gas, as the gas is diluted into the volume within the infant's chest. One study showed that severe respiratory distress syndrome was associated with low lung volumes often in the region of $9 \mathrm{ml} / \mathrm{kg} /$ body weight ${ }^{9}$ against an expected of 25 $\mathrm{ml} / \mathrm{kg} /$ body weight. ${ }^{1011}$

These techniques have now been used to assess the effects of surfactant in small pilot studies. One showed that natural surfactant treatment produces an increase in the FRC of $50-330 \%$ within 15 minutes mimicking the response time of the blood gas improvement. ${ }^{9}$ Our own study found that natural surfactant treatment was associated with a rise in FRC from $7.4 \mathrm{ml} / \mathrm{kg}$ to $10.7 \mathrm{ml}$ and $12.8 \mathrm{ml} / \mathrm{kg}, 15$ minutes and six hours after surfactant treatment respectively (J Alexander, A D Milner, unpublished data).

Similar changes are seen after artificial surfactants such as Exosurf, but these take at least six hours to become evident (J Alexander and A D Milner, unpublished data). Additional information has been derived by using the nitrogen washout technique on babies on ventilators. ${ }^{12}$ This study again showed a dramatic improvement in lung volume, although the initial pretreatment values were surprisingly high ranging from $17-31 \mathrm{ml}$.

In a single study, fluorocarbon was added to 'the bag in the bottle' system (J Alexander, A D Milner, unpublished data). As this gas is highly soluble in blood, the effective pulmonary blood flow, that is the blood coming into direct contact with ventilated alveoli, can be measured from the rate of disappearance of the gas. ${ }^{13}$ This showed that surfactant treatment was associated with an $18 \%$ increase in effective pulmonary blood flow. In this relatively small study, this failed to reach statistical significance. As studies using Doppler methods have not demonstrated any increase in total pulmonary blood flow following surfactant treatment, ${ }^{14}$ this increase if confirmed, must result from a reduction in the right to left shunt through poorly or non-ventilated areas.

What has remained difficult to explain is why these quite dramatic improvements in lung expansion are not associated with simultaneous improvement in lung compliance. One suggestion is that although aeration may have improved, the infant's lung is still being ventilated at the extreme of the pressure volume loop, hiding any change in the elastic characteristics of the lung. ${ }^{9} 12$ Secondly, probably the most important role of surfactant is not to make inspiration easier, but rather to stabilise the alveoli on expiration so that an adequate FRC can be achieved. Thus, administration of surfactant would tend to limit the amount of air escaping from the lung when either inspiratory effort or inspiratory inflation has ceased, leading to a reduction rather than increase in the compliance measurement after exogenous surfactant (E Bancalari, personal communication).

The area has been further muddled by a report from North America, ${ }^{3}$ in which although improvements in lung mechanics were not apparent for up to 24 hours after treatment with natural surfactant in babies requiring ventilatory support, the compliance of babies breathing spontaneously showed a $29 \%$ increase within one hour of 
treatment. These differences may be due to the fact that the compliance measurements were obtained using different techniques by dividing tidal volume by ventilator pressure swing in those receiving intermittent positive pressure ventilation (IPPV) while those breathing spontaneously were studied by dividing tidal volume by oesophageal pressure. ${ }^{15}$

More recently, there have been studies claiming that improvements in lung function can be documented by measuring the total respiratory system compliance. ${ }^{16}$ This is achieved by occluding the airway at the top of a ventilator breath, and then venting the respiratory system to atmosphere, using the associated fall in pressure and volume for the calculation. Several studies have shown that even 2-3 cm of positive end expiratory pressure can reduce lung compliance due to the shape of the deflationary pressure volume loop. ${ }^{17}$ This could be hiding some of the improvement in babies receiving IPPV.

It will obviously be necessary to carry out further studies to resolve the controversies over the short term compliance measurements, although all investigators are agreed that in the longer term, improvements will occur. What is now generally accepted is that exogenous surfactant increases aeration and probably effective pulmonary blood flow, and that these are responsible for the immediate improvements in oxygenation.

A D MILNER

Division of Paediatrics,

St Thomas's Hospital (UMDS),

Lambeth Palace Road,

London SE1 7EH

1 Avery ME, Mead J. Surface properties in relation to atelectasis and hyaline membrane disease. Am $\mathcal{F}$ Dis Child 1959;97:517-23.

2 Fujiwara T, Chida SA, Watabe J, Maeta H, Morita T, Abe T. Artificial surfactant therapy in hyaline-membrane disease. Lancet 1980;i:55-9.
3 Davis JM, Veness-Meechan K, Notter RH, Bhutani VK, Kendig JW, Shapiro DL. Changes in pulmonary mechanics after the administration of surfactant to infants with respiratory distress syndrome. $N$ Engl $\mathcal{F}$ Med 1988;319:476-9.

4 Tamura M, Kawano T. The effect of reconstituted bovine surfactant of pulmonary mechanics in infants with respiratory distress syndrome. Acta pulmonary mechanics in infants with respiratory
Paediatr fpn (Overseas edition) 1989;31:734-41.

5 Bhat R, Dziedzic K, Bhutani VK, Vidasagar D. Effect of single dose surfactant on pulmonary function. Crit Care Med 1990;18:590-5.

6 Couser RJ, Ferrara TB, Ebert J, Hoekstra RE, Fangman JJ. Effects of exogenous surfactant therapy on dynamic compliance during mechanical breathing in preterm infants with hyaline membrane disease. 7 Pediatr 1990;116:119-24.

7 Gitlin JD, Soll RF, Parad RB, et al. Randomized controlled trial of exogenous surfactant for the treatment of hyaline membrane disease. Pediatrics 1987;79:31-7.

8 Schwartz JG, Fox WW, Shaffer TH. A method for measuring function residual capacity in neonates with endotracheal tubes. IEEE Trans Biomed Eng 1978;25:304-7.

9 Goldsmith LS, Greenspan JS, Rubenstein D, Wolfson MR, Schaffer TH. Immediate improvement in lung volume after exogenous surfactant: alveolar recruitment versus increased distension. F Pediatr 1991;119:424-8.

10 Geubelle F, Francotte M, Beyer M, Louis I, Logvnoff MM. Functional residual capacity and thoracic gas volume in normoxic and hyperoxic newborn infants. Acta Paediatrica Belgica 1977;30:221-5.

11 Boon AW, Ward-McQuaid JMC, Milner AD, Hopkin IE. Thoracic gas volume, helium functional residual capacity and air-trapping in the first six hours of life: the effect of oxygen administration. Early Hum Dev $1981 ; 5: 157-66$.

12 Edberg KE, Ekstrom-Jodal B, Hallman M, Hjalmarson O, Sandberg K, Silberberg A. Immediate effects on lung function of instilled human surfactant in mechanically ventilated newborn infants with IRDS. Acto Paediatr Scand 1990;79:750-5.

13 Bush A, Busst CM, Johnson S, Denison DM. Rebreathing method for the simultaneous measurement of oxygen consumption and effective pulmonary blood flow during exercise. Thorax 1988;43:268-75.

14 Halliday HL, McCord FB, McClure BG, McReid M. Acute effects on instillation of surfactants in severe respiratory distress syndrome. Arch Dis Child 1989;64:13-6.

15 Mammel MC, Fisher JB, Bing DR, Gatto CW, Boros SJ. Effect of spontaneous and mechanical breathing on dynamic lung mechanics in hyaline membrane disease. Pediatr Pulmonol 1992;8:222-5.

16 Pfenninger J, Aebi C, Bachmann D, Wagner BP. Lung mechanics and gas exchange in ventilated pre term infants during treatment of hyaline membrane disease with multiple doses of artificial surfactant (Exosurf). Pediatr Pulmonol 1992;14:10-5.

17 Field DJ, Milner AD, Hopkin IE. Effects of positive end expiratory pressure in the ventilation of premature infants. Arch Dis Child 1985;60:843-8. 